\title{
Stereocomplex crystallization and homo-crystallization of star-shaped four-armed stereo diblock poly(lactide)s during precipitation and non-isothermal crystallization
}

\author{
Hideto Tsuji, Nobutsugu Matsumura and Yuki Arakawa \\ Polymer Journal (2016) 48, 1087-1093; doi:10.1038/pj.2016.73; published online 31 August 2016
}

\section{INTRODUCTION}

Poly(L-lactide) (PLLA) is a biobased biodegradable polyester that can be used in various applications, such as commodity, industrial, biomedical, pharmaceutical and environmental applications. ${ }^{1}$ The stereocomplexed materials from enantiomeric PLLA and poly (D-lactide) (PDLA) have attracted much attention as advanced poly (lactide) (PLA)-based materials because of their superior mechanical performance as well as the hydrolytic/thermal degradation resistance of stereocomplexed PLA materials compared with that of conventional PLA-based materials. ${ }^{2-4}$ Stereocomplex (SC)-crystallization in enantiomeric polymer blends containing both linear one-armed PLLA and PDLA (1-L and 1-D, respectively $)^{2-8}$ and linear one-armed stereoblock copolymers $^{2-4,9-12}$ has been extensively studied. Stereoblock copolymerization is effective at facilitating SC-crystallization because PLLA and PDLA blocks are next to each other. The effects of the star-shaped or branching architecture on SC-crystallization were investigated using blends of both multiarmed PLLA and PDLA, ${ }^{13}$ blends of 1-L and multiarmed PDLA and multiarmed PLLA and $1-\mathrm{D}^{14}$ and miktoarmed PLLA and PDLA. ${ }^{15} \mathrm{~A}$ star-shaped or branching architecture disturbs the SC-crystallization.

Similar to linear one-armed stereoblock PLA, ${ }^{11}$ only SC-crystallites were formed in star-shaped four-armed stereo diblock equimolar PLA (4-LD) polymers. ${ }^{16}$ In the present article as well as in previous articles, 'equimolar' means that a polymer contains the same amounts of L- and D-lactyl units. Recently, stereo diblock copolymers of PLA polymers with different arm numbers and high molecular weights were synthesized, and their isothermal and non-isothermal crystallization was investigated. ${ }^{17}$ The melting temperature, degree of crystallinity, spherulitic growth rate, crystallite size, long period and crystalline layer thickness of stereo diblock copolymers of PLA polymers decreased with increasing branch number owing to the retarding effect of branching on the crystallization rate and crystallizability. In previous studies, ${ }^{16,18}$ we investigated the static isothermal crystallization of star-shaped 4- $\mathrm{LD}$ polymers with different molecular weights or different L-lactyl unit contents as well as a star-shaped 4-L polymer from the melt. Only
SC-crystallites were formed in 4-LD in a L-lactyl unit range from $31 \%$ to $72 \%$. Both branching and diblock architectures disturbed the SC-crystallization and spherulite growth of equimolar 4-LD polymers, and the effect of the disturbance was larger for branching architectures than for diblock architectures. However, the branching architecture primarily hindered the simultaneous formation of SC- and homocrystallites of non-equimolar 4-LD polymers.

In the present study, the crystallization of equimolar 4-LD polymers with different molecular weights and four-armed PLLA (4-L) and 4-LD polymers with different L-lactyl unit contents were investigated during precipitation or non-isothermal crystallization.

\section{EXPERIMENTAL SECTION}

The preparation of the materials and the methods of measurement and observation utilized in the present study are described in Supplementary Information (Section S1). The molecular characteristics of the polymers used in the present study are summarized in Table 1, and the molecular structure of $4-\mathrm{LD}$ is shown in Figure 1 along with those of 1 -armed stereo diblock PLA (1-LD), 4-L/4-armed PDLA (4-D) and 1-L/1-D blend.

\section{RESULTS}

\section{Precipitation}

Figures $2 \mathrm{a}$ and $\mathrm{b}$ show the wide-angle X-ray scattering (WAXD) profiles of the precipitated polymers, and Supplementary Figure S1 shows the magnified WAXD profiles of precipitated 4-L11D5 and 4-L4D11. All the precipitated polymers were crystallizable during precipitation. The equimolar 4-LD polymers exhibited only SC-crystalline diffraction peaks at 12,21 and $24^{\circ}$ (Figure 2a), indicating the sole formation of SC-crystallites in the absence of homo-crystallites irrespective of $M_{\mathrm{n}}$. However, 4-L polymer 4-L16 (100) and non-equimolar 4-L14D2(93) exhibited only $\alpha$-form homocrystalline peaks at $12.5,15,17,19$ and $22.5^{\circ},{ }^{16,18}$ and non-equimolar 4-L11D5(72) and 4-L4D11(31) (Supplementary Figure S1) exhibited only SC-crystalline peaks at 12 and $21^{\circ}$. The WAXD results indicated 
Table 1 Molecular characteristics of 4-L homopolymers and 4-LD copolymers synthesized in the present study ${ }^{16,18}$

\begin{tabular}{|c|c|c|c|c|c|c|c|}
\hline Code $\mathrm{a}^{\mathrm{a}}$ & Coinitiator & $\begin{array}{l}\text { Lactide/coinitiator } \\
\text { (mol/mol) or (w/w) }\end{array}$ & $\begin{array}{l}\mathrm{M}_{n}(N M R)^{\mathrm{b}} \\
\left(g \mathrm{~mol}^{-1}\right)\end{array}$ & $\begin{array}{l}\mathrm{M}_{n}(G P C)^{\mathrm{b}} \\
\left(g \mathrm{~mol}^{-1}\right)\end{array}$ & $\begin{array}{c}\mathrm{M}_{w}(G P C) \mathrm{M}_{n} \\
(G P C)^{b}\end{array}$ & $\begin{array}{c}{[\alpha]^{25} 589^{\mathrm{c}}} \\
\left(\operatorname{deg} \mathrm{dm}^{-1} \mathrm{~g}^{-1} \mathrm{~cm}^{-3}\right)\end{array}$ & $\begin{array}{l}\text { L-lactyl unit } \\
\text { content (\%) }\end{array}$ \\
\hline 4-L4 & Pentaerythritol & $26.8^{\mathrm{d}}$ & $4.40 \times 10^{3}$ & $6.30 \times 10^{3}$ & 1.10 & -153.3 & - \\
\hline 4-L8 & & $68.4^{d}$ & $8.37 \times 10^{3}$ & $1.66 \times 10^{4}$ & 1.28 & -173.5 & - \\
\hline 4-L11 & & $82.3^{d}$ & $1.05 \times 10^{4}$ & $2.19 \times 10^{4}$ & 1.12 & -163.5 & - \\
\hline 4-L14 & & $117.1^{\mathrm{d}}$ & $1.43 \times 10^{4}$ & $2.73 \times 10^{4}$ & 1.07 & -172.1 & - \\
\hline 4-L8D8 & 4-L8 & & $1.62 \times 10^{4}$ & $3.52 \times 10^{4}$ & 1.08 & -3.4 & 51.0 \\
\hline 4-L16D15 & 4-L16 & & $-^{f}$ & $5.45 \times 10^{4}$ & 1.08 & -4.5 & 51.3 \\
\hline 4-L14D2 & 4-L14 & $7 / 93^{e}$ & $1.60 \times 10^{4}$ & $2.90 \times 10^{4}$ & 1.26 & -151.9 & 93.4 \\
\hline 4-L11D5 & 4-L11 & $30 / 70^{e}$ & $1.62 \times 10^{4}$ & $3.12 \times 10^{4}$ & 1.08 & -76.0 & 71.7 \\
\hline 4-L4D11 & 4-L4 & $70 / 30^{e}$ & $1.53 \times 10^{4}$ & $2.64 \times 10^{4}$ & 1.24 & 68.1 & 30.6 \\
\hline
\end{tabular}

Abbreviations: GPC, gel permeation chromatography; NMR, nuclear magnetic resonance; 4-L, 4-armed poly(lactide); 4-LD, 4-armed stereo diblock poly(lactide).

aThe figure following the letters indicates the $M_{\mathrm{n}}$ value/10 3 .

${ }^{\mathrm{b}} M_{\mathrm{n}}$ and $M_{\mathrm{w}}$ are the number- and weight-average molecular weights, respectively.

cSpecific optical rotation measured in a mixed solvent consisting of chloroform/HFIP (vol/vol =95/5).

d In $\mathrm{mol} / \mathrm{mol}$.

eln $w / w$.

${ }^{\mathrm{f}} M_{\mathrm{n}}$ (NMR) could not be obtained owing to the low fraction of hydroxyl terminal groups, and the molecular weight of the PDLA segments was estimated from the L-lactyl unit content.

that only $\alpha$-form homo-crystallization and SC-crystallization occurred in the former and latter samples, respectively, during precipitation. Based on the relative peak heights, the broad peaks at approximately 15 and $17^{\circ}$ in non-equimolar 4-L11D5(72) and 4-L4D11(31) may be due to the meta phase. For the 4-LD and 4-L polymers with different L-lactyl unit contents, the crystalline species changed from only SCcrystallites to only homo-crystallites with deviation of the L-lactyl unit content from $50 \%$, which is in contrast to that observed for the $1-\mathrm{L} / 1$ D blends. ${ }^{9}$ In these blends, the crystalline species changed from only SC-crystallites to both SC- and homo-crystallites and then to only homo-crystallites. The crystallinity $\left(X_{\mathrm{c}}\right)$ values of the homo-crystallites $\left(X_{\mathfrak{c}}(\mathrm{H})\right)$ and SC-crystallites $\left(X_{\mathrm{c}}(\mathrm{S})\right)$ of the precipitated polymers estimated from Figures $2 \mathrm{a}$ and $\mathrm{b}$ are listed in Supplementary Table S1. The $X_{\mathrm{c}}(\mathrm{S})$ values of the equimolar 4 -LD polymers $(45-56 \%)$ increased with increasing $M_{\mathrm{n}}$, and even an incorporation 7\% D-lactyl units in 4-L14D2 resulted in a $16 \%$ decrease in $X_{\mathrm{c}}(\mathrm{H})$ compared with that observed for the 4-L homopolymer (4-L16).

Figures $3 \mathrm{a}$ and $\mathrm{b}$ show the differential scanning calorimetric thermograms of the precipitated polymers for heating. The glass transition, cold crystallization and melting peaks were observed at $35-58^{\circ} \mathrm{C}, \quad 99-115^{\circ} \mathrm{C}$ and $130-213^{\circ} \mathrm{C}$, respectively. The thermal properties obtained from Figures $3 \mathrm{a}$ and $\mathrm{b}$ are tabulated in Supplementary Table S1. The melting peaks of the SC-crystallites of the equimolar $4-\mathrm{LD}$ polymers were observed at $130-213^{\circ} \mathrm{C}$. $4-\mathrm{L} 16$ (100) exhibited a cold crystallization peak and a melting peak for the homo-crystallites at 107 and $151^{\circ} \mathrm{C}$, respectively. However, 4-L14D2 (93), which contained 7\% D-lactyl units, had a lower $T_{\mathrm{cc}}$ and $T_{\mathrm{m}}$ for the homo-crystallites ( 99 and $145^{\circ} \mathrm{C}$, respectively) than those of the optically pure 4-L16. Based on the length of the longer L-lactyl unit block or D-lactyl unit block in 4-L11D5(72) and 4-L4D11(31) being shorter than that in 4-L14D2(93), 4-L11D5(72) and 4-L4D11(31) should exhibit $T_{\mathrm{m}}$ values lower than that of 4-L14D2 with only homocrystallites if these three polymers only formed homo-crystallites. However, the $T_{\mathrm{m}}$ values of 4-L11D5 and 4-L4D11 (156 and $143^{\circ} \mathrm{C}$, respectively) were higher than and similar to that of $4-\mathrm{L} 14 \mathrm{D} 2\left(145^{\circ} \mathrm{C}\right)$, indicating that these meting peaks correspond to SC-crystallites. The presence of cold crystallization peaks in the DSC thermograms and very low $X_{c}(S)$ values for 4 -L11D5 and 4-L4D11 indicate that, in addition to the SC-crystallites formed during precipitation, further SC-crystallization occurred during the DSC heating scan.

\section{Non-isothermal crystallization during heating}

Figures $3 \mathrm{c}$ and $\mathrm{d}$ show the DSC thermograms of the melt-quenched samples for heating. All the samples, excluding melt-quenched 4-L11D5(72) and 4-L4D11(31), exhibited cold crystallization, indicating SC- or homo-crystallizability during heating. The thermal properties obtained from Figures $3 \mathrm{c}$ and $\mathrm{d}$ are summarized in Supplementary Table S1. The similar $T_{\mathrm{m}}$ values of the precipitated and melt-quenched samples strongly suggest that the crystalline species formed during heating of the melt-quenched samples were the same as those formed during precipitation. Therefore, only SC-crystallites were formed in the equimolar 4-LD polymers (4-L5D, 4-L8D8 and 4-L16D15), and only homo-crystallites were formed in 4-L16 and 4-L14D2.

The $T_{\mathrm{g}}, T_{\mathrm{cc}}$ and $T_{\mathrm{m}}$ of the SC-crystallites $\left(T_{\mathrm{m}}(\mathrm{S})\right)$ values for equimolar 4-LD polymers are plotted in Figure 4 as a function of $M_{\mathrm{n}}(\mathrm{NMR})$ (nuclear magnetic resonance) ( $T_{\mathrm{g}}$ and $T_{\mathrm{cc}}$ ) or $M_{\mathrm{n}}(\mathrm{NMR})$ per one block $\left(T_{\mathrm{m}}(\mathrm{S})\right)$ along with those reported for equimolar 1-LD polymers ${ }^{11}$ and equimolar $4-\mathrm{L} / 4-\mathrm{D}$ and $1-\mathrm{L} / 1-\mathrm{D}$ blends. ${ }^{13}$ The linear one-armed 1-L/1-D blends exhibited the highest $T_{\mathrm{g}}$ values except for the $T_{\mathrm{g}}$ of the lowest molecular weight $1-\mathrm{LD}$ polymer. The $T_{\mathrm{g}}$ values decreased with the factors of the branching and diblock architectures, and the $T_{\mathrm{g}}$ values of the $4-\mathrm{LD}$ and 1-LD polymers were lower than those of the 4-L/4-D and 1-L/1-D blends, respectively. The $T_{\mathrm{g}}$ values of the 4-LD and 1-LD polymers were similar to one another and the lowest among the samples. However, the $T_{\mathrm{cc}}$ values do not appear to be affected by the branching and diblock architectures. The $T_{\mathrm{cc}}$ of the 4-L/4-D blends and 1-LD polymers increased in the low temperature range even though $T_{\mathrm{cc}}$ typically decreases with decreasing $M_{\mathrm{n}}$, as observed for the 1-L/1-D blends. The $T_{\mathrm{m}}(\mathrm{S})$ values of the $1-\mathrm{L} / 1-\mathrm{D}$ and 4-L/4-D blends as well as the 1-LD and 4-LD polymers were determined by the $M_{\mathrm{n}}$ (NMR) values per one block and not $M_{\mathrm{n}}$ (NMR) or $M_{\mathrm{n}}$ (NMR) per one arm (Supplementary Figure S2). Therefore, the $T_{\mathrm{m}}(\mathrm{S})$ values were determined by the $M_{\mathrm{n}}(\mathrm{NMR})$ values per one block and are not affected by the presence of branching moiety points or turnover points. However, the $-\Delta H_{\mathrm{cc}}$ values of the equimolar $4-\mathrm{LD}$ polymers as an index of the maximum crystallinity 


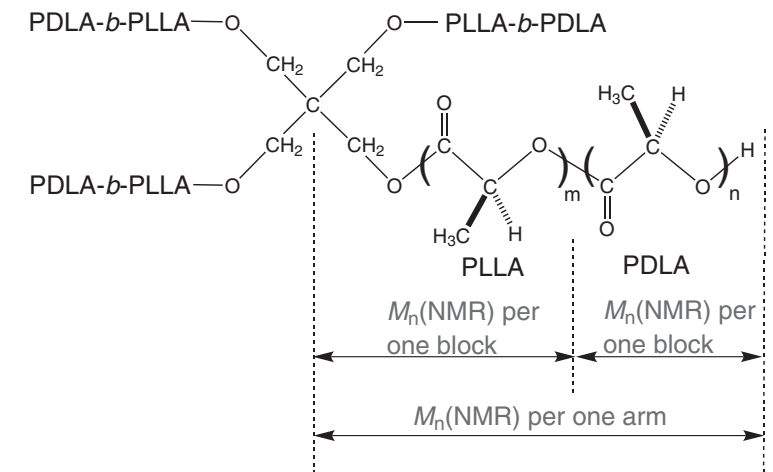

b

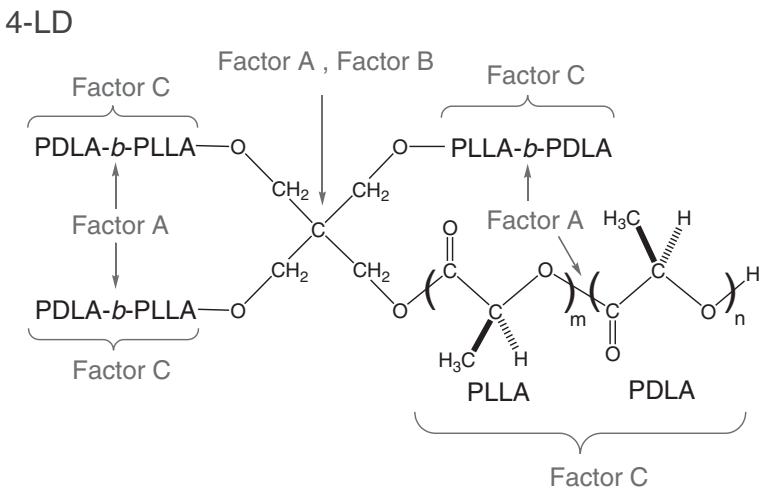

1-LD

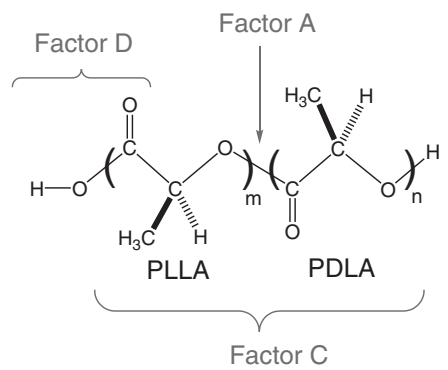

4-L/4-D Factor A, Factor B<smiles>[1H]C(C)(O[10CH])C(=O)OCC(COCCC)(COCCC)COCCC</smiles>

Factor A, Factor B

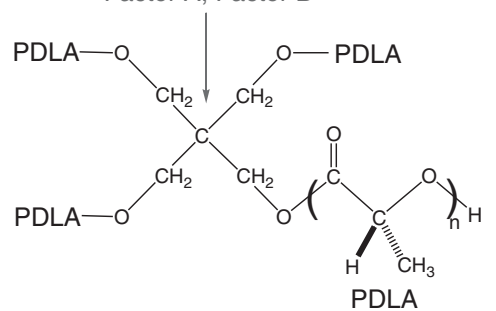

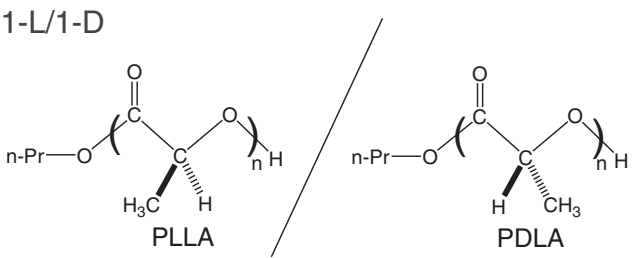

Figure 1 Molecular structure of 4-LD, $M_{n}(N M R)$ per one arm and $M_{n}(N M R)$ per one block (a) and molecular structure of 4-LD, 1-LD, 4-L/4-D and 1-L/1-D blends. Factor A (branching or turnover points), Factor B (intersegmental connection), Factor C (presence of PLLA and PDLA segments in a same molecule) and Factor D (presence of terminal carboxyl group) (b). A full color version of this figure is available at the Polymer Journal online.

during heating were constant in the $42-45 \%$ range, and the $-\Delta H_{c c}$ values of non-equimolar 4 -LD polymers were nil. The $-\Delta H_{\mathrm{cc}}$ value of 4-L16 (35\%) substantially decreased upon incorporation of $7 \%$ D-lactyl units (4-L14D2, 7\%).

The Flory-Fox and Flory equations were utilized to estimate the $T_{\mathrm{g}}$ and $T_{\mathrm{m}}$ values at infinite molecular weight $\left(T_{\mathrm{g}}{ }^{\infty}\right.$ and $T_{\mathrm{m}}{ }^{\infty}$, respectively) (Section S5 including Supplementary Figure S3). Here, owing to the extraordinary trend stated in the Discussion section, the results for the 1-LD polymers are not compared with those for other samples. The estimated $T_{\mathrm{g}}{ }^{\infty}$ decreased in the following order: 1-L/1-D blends $\left(60.6{ }^{\circ} \mathrm{C}\right)>4$-L $/ 4$-D blends $\left(59.1^{\circ} \mathrm{C}\right)>4$-LD polymers $\left(53.2^{\circ} \mathrm{C}\right)$ for $M_{\mathrm{n}}(\mathrm{NMR})$ and $1-\mathrm{L} / 1-\mathrm{D}$ blends $\left(61.3^{\circ} \mathrm{C}\right)>4-\mathrm{L} / 4$-D blends $\left(58.1^{\circ} \mathrm{C}\right)$
$>4$-LD polymers $\left(54.8^{\circ} \mathrm{C}\right)$ for $M_{\mathrm{n}}(\mathrm{GPC})$ (gas permeation chromatography). The evaluated $K$ values or the excess free volume of the terminal groups decreased in the following order: 4-LD polymers $\left(1.2 \times 10^{5} \mathrm{~K} \mathrm{~g} \mathrm{~mol}^{-1}\right)>4$-L/4-D blends $\left(9.9 \times 10^{4} \mathrm{~K} \mathrm{~g} \mathrm{~mol}^{-1}\right)>1-\mathrm{L} /$ 1 -D blends $\left(8.9 \times 10^{4} \mathrm{~K} \mathrm{~g} \mathrm{~mol}^{-1}\right)$ for $M_{\mathrm{n}}(\mathrm{NMR})$ and 4 -LD polymers $\left(2.4 \times 10^{5} \mathrm{~K} \mathrm{~g} \mathrm{~mol}^{-1}\right)>1$-L/1-D blends $\left(1.4 \times 10^{4} \mathrm{Kg} \mathrm{mol}^{-1}\right)>4-\mathrm{L} /$ 4-D blends $\left(1.2 \times 10^{5} \mathrm{Kg} \mathrm{mol}^{-1}\right)$ for $M_{\mathrm{n}}(\mathrm{GPC})$. In addition, the estimated $T_{\mathrm{m}}{ }^{\infty}$ values decreased in the following order: 1-L/1-D blend $\left(255.3^{\circ} \mathrm{C}\right)>4$-L/4-D blends $\left(245.1^{\circ} \mathrm{C}\right)>4$-LD polymers $\left(222.9^{\circ} \mathrm{C}\right)$ for $M_{\mathrm{n}}(\mathrm{NMR})$ and $1-\mathrm{L} / 1-\mathrm{D}$ blend $\left(258.0^{\circ} \mathrm{C}\right)>4-\mathrm{L} / 4-\mathrm{D}$ blends $\left(240.0^{\circ} \mathrm{C}\right)>4$-LD polymers $\left(220.0^{\circ} \mathrm{C}\right)$ for $M_{\mathrm{n}}(\mathrm{GPC})$. These results indicate that the branching and stereo diblock architectures affect the 
a

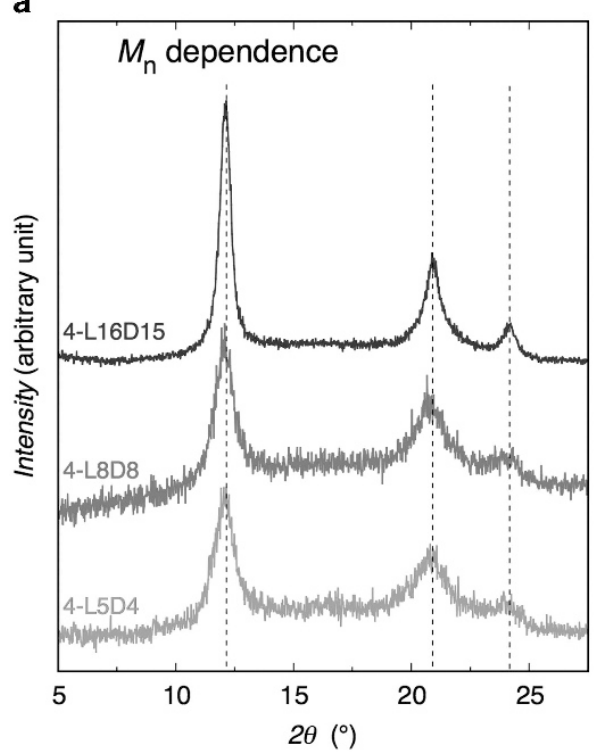

c

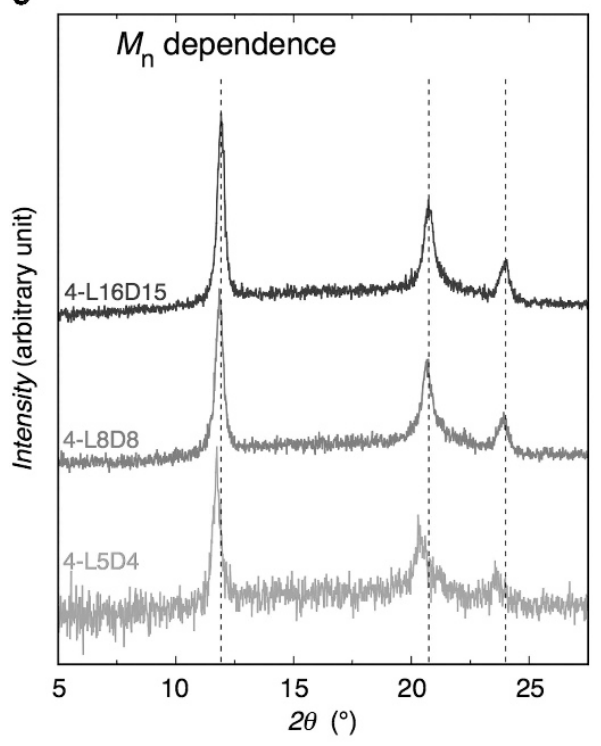

b

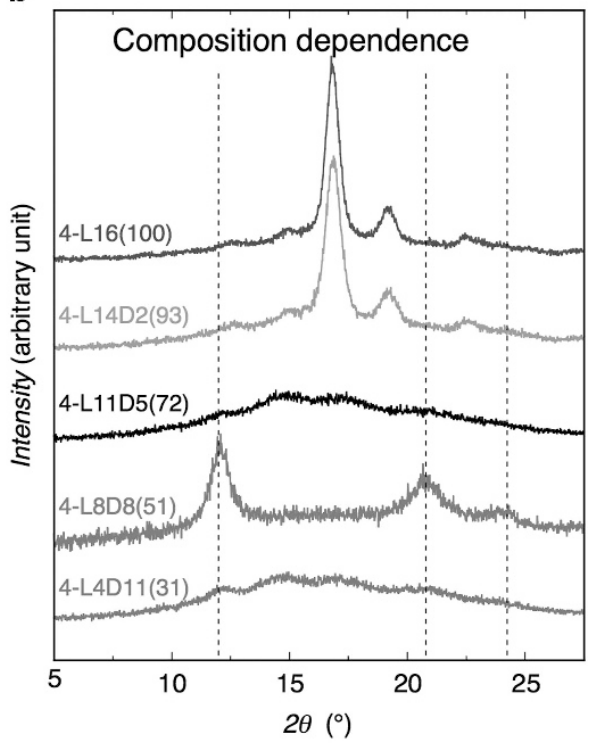

d

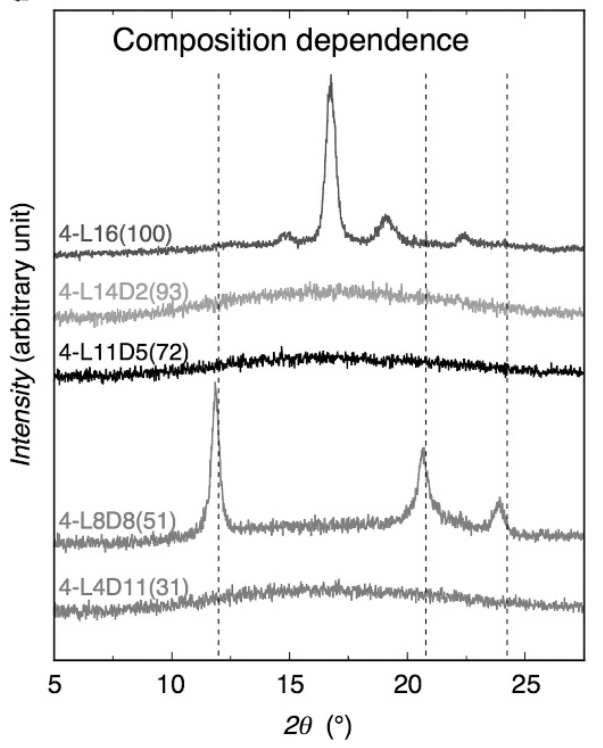

Figure 2 WAXD profiles of precipitated equimolar 4-LD polymers with different $M_{\mathrm{n}}$ values (a) and precipitated 4-LD and 4-L polymers with similar $M_{\mathrm{n}}$ values and different L-lactyl unit contents (b). WAXD profiles of precipitated equimolar 4-LD polymers with different $M_{\mathrm{n}}$ values (c) and 4-LD and 4-L polymers with similar $M_{\mathrm{n}}$ values and different L-lactyl unit contents (d) after slow cooling from the melt. The values in the parentheses in panels (b and $\mathbf{d}$ ) are the $\mathrm{L}$-lactyl unit contents. A full color version of this figure is available at the Polymer Journal online.

chain mobility, excess free volume and crystalline size and disorder at infinite $M_{\mathrm{n}}$.

\section{Non-isothermal crystallization during cooling}

Figures $3 \mathrm{e}$ and $\mathrm{f}$ show the DSC thermograms of the precipitated samples for slow cooling from the melt. The thermal properties estimated from Figures $3 \mathrm{e}$ and $\mathrm{f}$ are summarized in Supplementary Table S2. Although equimolar 4-LD polymers and 4-L16 were crystallizable during slow cooling, other polymers were non-crystallizable during slow cooling. In contrast, 4-L14D2 was crystallizable during precipitation and heating as well as isothermal crystallization for $3 \mathrm{~h},{ }^{18}$ and 4-L11D5 and 4-L4D11 were crystallizable during precipitation as well as isothermal crystallization for $24 \mathrm{~h} .{ }^{18}$ As expected, the sample with a high $T_{\mathrm{m}}$ had a high $T_{\mathrm{c}}$ and onset temperature of crystallization.

Figures $2 \mathrm{c}$ and $\mathrm{d}$ show the WAXD profiles of the samples after slow cooling from the melt. The $X_{\mathrm{c}}(\mathrm{H})$ and $X_{\mathrm{c}}(\mathrm{S})$ values were evaluated from Figures $2 \mathrm{c}$ and $\mathrm{d}$ and summarized in Supplementary Table S2. 4-L5D4, 4-L8D8 and 4-L16D15 were crystallized during slow cooling, which is in agreement with the DSC results, and only crystalline diffraction peaks at 12,21 and $24^{\circ}$ that correspond to SC-crystallites were observed for all the equimolar 4-LD polymers. This result indicates the sole formation of SC-crystallites in the equimolar 4-LD polymers without the formation of homo-crystallites irrespective of $M_{\mathrm{n}}$. However, for 4-L and non-equimolar 4-LD polymers, only 4-L16 (100) was crystallizable during slow cooling, and only $\alpha$-form homocrystalline peaks were observed at $15,17,19$ and $22.5^{\circ}$. 
a

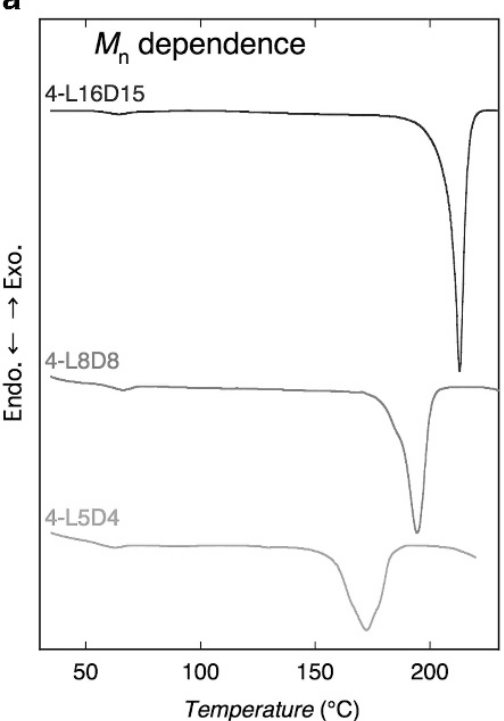

d

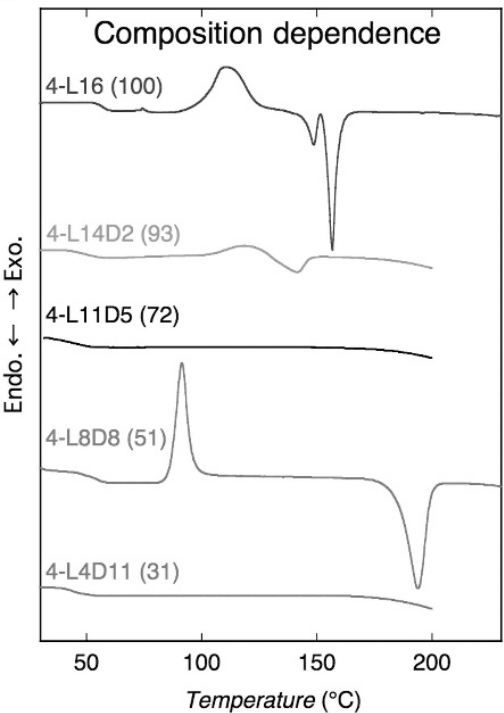

b

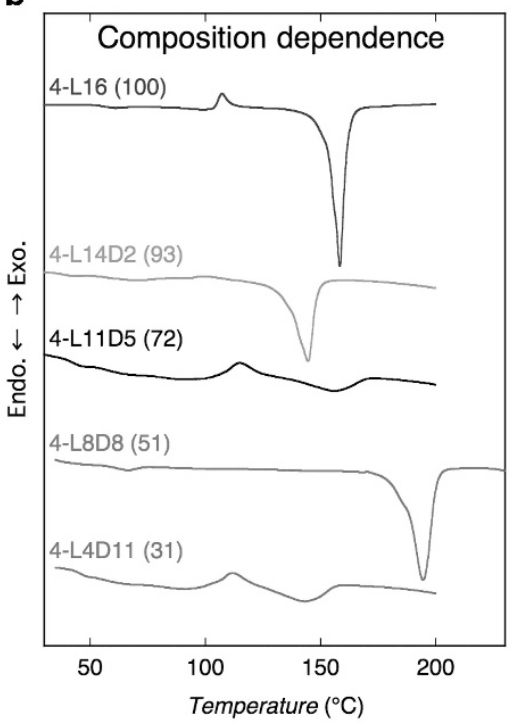

e

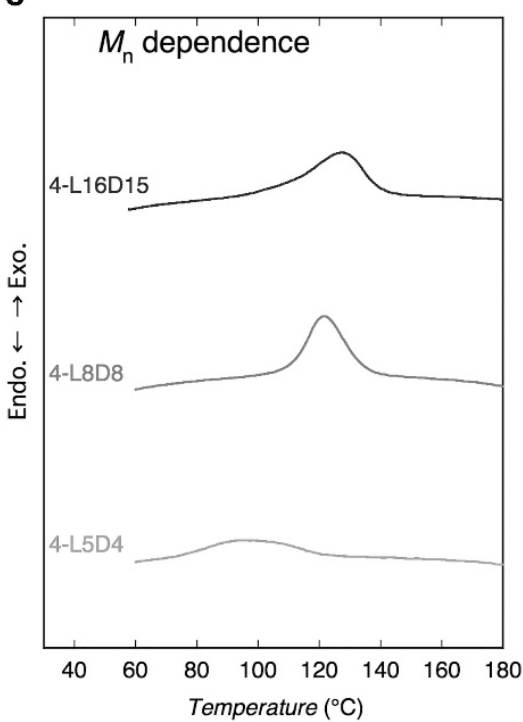

c

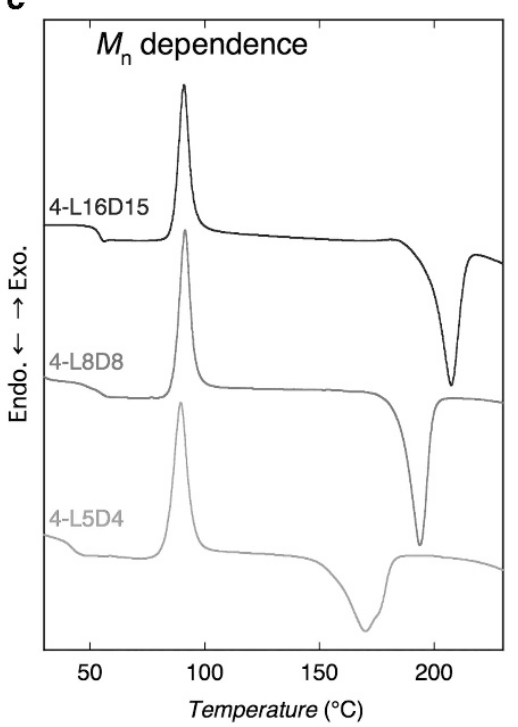

f

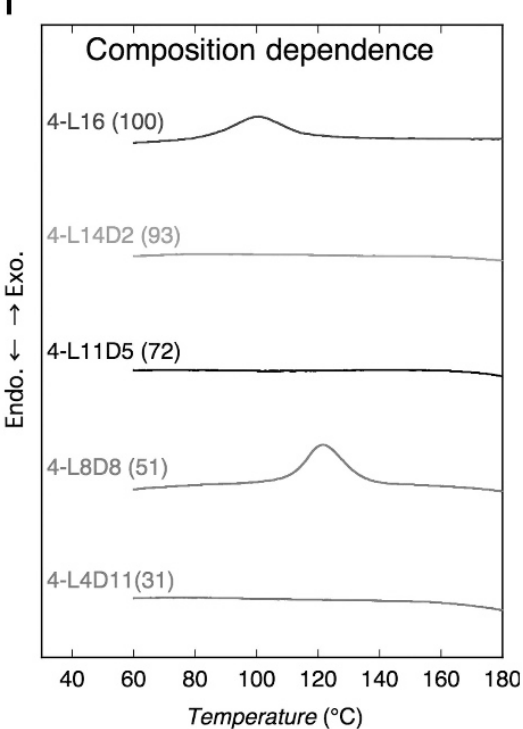

Figure 3 DSC thermograms of precipitated (a, b) and melt-quenched (c, d) equimolar 4-LD polymers with different $M_{\mathrm{n}}$ values (a, c) and precipitated 4-LD and 4-L polymers with similar $M_{n}$ values and different L-lactyl unit contents $(\mathbf{b}, \mathbf{d})$ for heating. DSC thermograms of precipitated equimolar 4-LD polymers with different $M_{\mathrm{n}}$ values (e) and 4-LD and 4-L polymers with similar $M_{\mathrm{n}}$ values and different L-lactyl unit contents (f) for slow cooling from the melt. The values in the parentheses in panels (b, $\mathbf{d}$ and $\mathbf{f}$ ) are the L-lactyl unit contents. A full color version of this figure is available at the Polymer Journal online.

\section{Avrami analysis}

The overall crystallization kinetics that was traced by DSC was analyzed according to the Avrami theory (Supplementary Information (Section S6 including Supplementary Figures S4-S7)). The values of the Avrami exponent $(n)$, crystallization rate constant $(k)$ and experimental and calculated crystallization half times $\left(t_{\mathrm{c}}(1 / 2)\right.$ $(\exp )$ and $t_{\mathrm{c}}(1 / 2)(\mathrm{cal})$, respectively) are summarized in Supplementary Table S3. For heating, assuming thermal nucleation, the $n$ values of equimolar 4-LD polymers (that is, approximately 5 ) indicate a solid sheaf growth morphology, and $n$ values of approximately 3 for 4 -L16 and 4 -L14D2 indicate a circular growth morphology. ${ }^{19}$ These results strongly suggest that the growth morphology was dependent on the crystalline species (SC- or homo-crystallites). For slow cooling, the $n$ values of equimolar 4-LD polymers increased from 2.15 for 4-L5D4 to 3.49 for $4-\mathrm{L} 16 \mathrm{D} 15$ with an increase in $M_{\mathrm{n}}$, indicating a fibrillar or circular growth morphology assuming thermal nucleation, and an $n$ value of 4-L16 (2.68) reflects the circular growth morphology. The $n$ values of equimolar 4-L8D8 (3.03) and optically pure 4-L16 (2.68) possessed similar $M_{\mathrm{n}}$ values, indicating that the type of crystalline species or block copolymerization does not affect the growth morphology.

\section{DISCUSSION}

As the $M_{\mathrm{n}}$ of branching polymers or stereo diblock copolymers (4-LD and 1-LD polymers, 4-L/4-D blends) decreased, the effects of branching or turnover points where the change in the chain direction or configuration occurs become higher owing to increased branching or turnover points per unit mass at a lower molecular weight. These branching or turnover points should disturb close packing or interactions between the segments and increase the free volume 
a

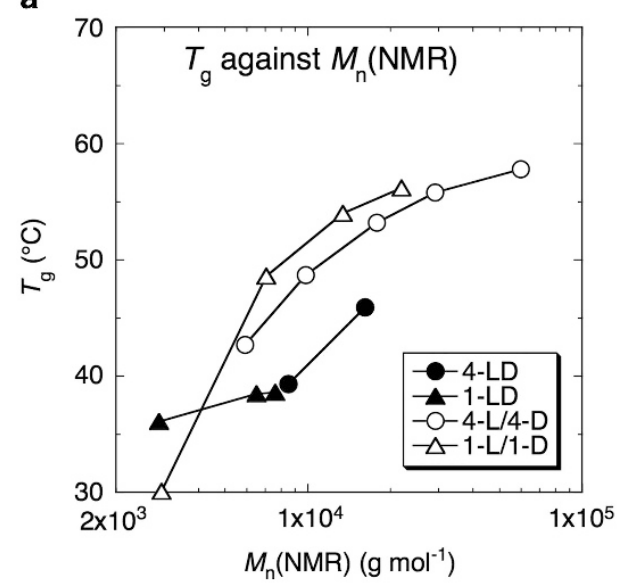

c

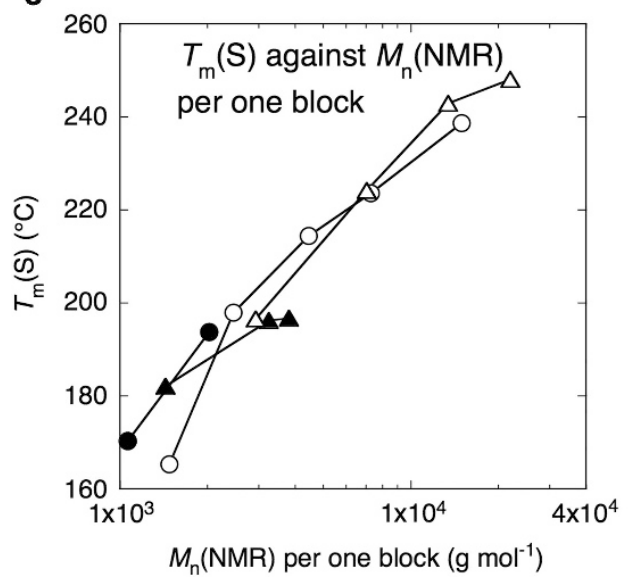

b

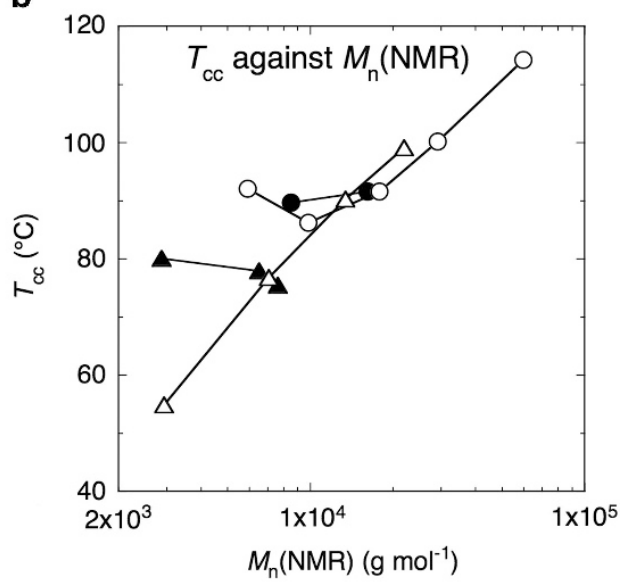

d

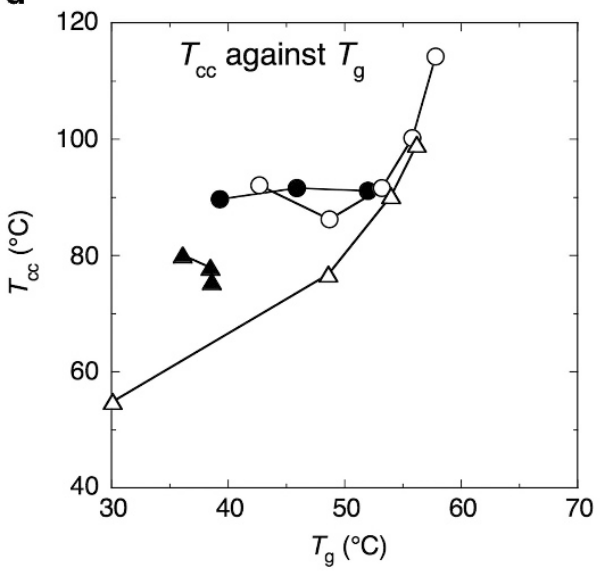

Figure $4 T_{\mathrm{g}}(\mathrm{a})$ and $T_{\mathrm{cc}}(\mathbf{b})$ as a function of $M_{\mathrm{n}}(\mathrm{NMR}), T_{\mathrm{m}}(\mathrm{S})$ as a function of $M_{\mathrm{n}}(\mathrm{NMR})$ per one block (c) and $T_{\mathrm{cc}}$ as a function of $T_{\mathrm{g}}$ (d) for equimolar 4-LD and 1-LD polymers as well as the 4-L/4-D and 1-L/1-D blends. $T_{\mathrm{g}}, T_{\mathrm{cc}}$ and $T_{\mathrm{m}}(\mathrm{S})$ values for equimolar 1-LD and 4-L/4-D as well as the 1-L/1-D blends are those reported in Tsuji et al. ${ }^{11}$ and Sakamoto and Tsuji ${ }^{13}$, respectively.

(Factor A). This factor will increase the segmental mobility, resulting in a decrease in $T_{\mathrm{g}}$ and $T_{\mathrm{cc}}$ or acceleration of cold crystallization. The intersegmental connection (4-LD polymers, 4 -L/4-D blends) owing to branching moieties is expected to lower the segmental mobility and disturb segmental diffusion to the crystalline growth sites (Factor B), resulting in an increase in $T_{\mathrm{g}}$ and $T_{\mathrm{cc}}$ or delayed cold crystallization. As reported for two-armed PLLA/PDLA blends and PLLA- $b$-PDLA, ${ }^{20}$ the presence of PLLA and PDLA segments in the same molecule (Factor C) (for example, 4-LD and 1-LD polymers) can disturb SC-crystallization compared with that of homopolymer blends (4-L/4-D blends and 1-L/1-D blends, respectively) even though the detailed mechanism for this factor has not been clarified. In addition, it is important to note that the terminals of $4-\mathrm{LD}$ and $4-\mathrm{L} / 4-\mathrm{D}^{13}$ are hydroxyl groups, and the terminals of 1-L/1-D are hydroxyl and $n$-propyl ester groups. ${ }^{13}$ However, the terminals of 1-LD are hydroxyl and carboxyl groups. ${ }^{11}$ The presence of terminal carboxyl groups in 1-LD, which can form strong hydrogen bonds with ester groups inside the chain, terminal hydroxyl groups or terminal carboxyl groups, will increase the interchain interaction (Factor D), which will increase the seeming molecular weight and result in decreased segmental mobility (that is, high $T_{\mathrm{g}}$ ) and disturbed segmental diffusion to the crystalline growth site (that is, high $T_{\mathrm{cc}}$ ), especially at a low $M_{\mathrm{n}}$ value. The extraordinary trends in $T_{\mathrm{g}}$ and $T_{\mathrm{cc}}$ for the lowest molecular weight of
1-LD observed in Figure 4 and Supplementary Figure S3 are due to Factor D. Factors A-D are illustrated in Figure $1 \mathrm{~b}$.

The lower $T_{\mathrm{g}}$ values of the 4-LD and 1-LD polymers compared with those of the 4-L/4-D and 1-L/1-D blends, respectively (Figure 4a), were due to Factor A regarding the turnover points of the configurational change. However, despite the addition of Factor B to 1-LD, the unaltered $T_{\mathrm{g}}$ values of 4 - $\mathrm{LD}$ compared with those of the 1-LD polymers indicates that Factor A for the branching moieties, Factor $\mathrm{B}$ and Factor $\mathrm{D}$ were counterbalanced. For further discussion, $T_{\mathrm{cc}}$ is replotted in Figure $4 \mathrm{~d}$ as a function of $T_{\mathrm{g}}$ to exclude the effects of segmental mobility on $T_{\mathrm{cc}}$. Based on the $T_{\mathrm{cc}}$ values shown in this plot, cold crystallization was disturbed in the following order: 4-LD polymers $\approx 4-\mathrm{L} / 4-\mathrm{D}$ blends $>1-\mathrm{LD}$ polymers $>1-\mathrm{L} / 1-\mathrm{D}$ blends. This result indicates that the disturbed cold crystallization was observed for the 4-L/4-D blends as well as the 4-LD and 1-LD polymers compared with the 1-L/1-D blends. When the effects of segmental mobility are excluded, the higher $T_{\mathrm{cc}}$ values of the $4-\mathrm{L} / 4-\mathrm{D}$ blends and $4-\mathrm{LD}$ polymers compared with those of the 1-L/1-D blends may be due to disturbed segmental diffusion (Factor B). The high $T_{\mathrm{cc}}$ values of the 1LD polymers compared with those of the 1-L/1-D blends were due to disturbed segmental diffusion (Factor D). It is interesting to note that the similar $T_{\mathrm{cc}}$ values for the 4-L/4-D blends and 4-LD polymers indicate that further addition of Factor $\mathrm{C}$ does not disturb the cold crystallization. 
SC-crystallization of 4-L11D5(72) and 4-L4D11(31), which required isothermal crystallization for $24 \mathrm{~h}$ from the melt, ${ }^{18}$ could be readily attained by precipitation in a short time period, such as several seconds. The crystalline species changed directly from only SC-crystallites to amorphous and then to only homo-crystallites (during non-isothermal crystallization) or from only SC-crystallites to only homo-crystallites (during precipitation) with deviation of L-lactyl unit content from $50 \%$. This result is in contrast to the result for 1-LD, where these crystalline species changed from only SC-crystallites to both SC- and homo-crystallites and then to only homo-crystallites. ${ }^{9}$ A comparison of the results for the 4-LD and 1-LD polymers strongly suggests that the branching architecture rather than the diblock architecture disturbed the simultaneous formation of SC- and homo-crystallites.

\section{CONCLUSIONS}

All the equimolar 4-LD polymers formed only SC-crystallites during precipitation, heating from ambient temperature or slow cooling from the melt irrespective of $M_{\mathrm{n}}$. During precipitation, the 4-L and non-equimolar 4-LD polymers with L-lactyl unit contents of $100 \%$ and $93 \%$ formed only $\alpha$-form homo-crystallites, and non-equimolar 4-LD polymers with L-lactyl unit contents of $72 \%$ and $31 \%$ formed only SC-crystallites. During heating, the 4-L and non-equimolar 4-LD polymers with L-lactyl unit contents of $100 \%$ and $93 \%$ formed only homo-crystallites, and the other non-equimolar 4-LD polymers were non-crystallizable. During slow cooling, the 4-L homopolymer formed only $\alpha$-form homo-crystallites, and the other non-equimolar 4 -LD polymers were non-crystallizable. With the deviation of the L-lactyl unit content from $50 \%$, the crystalline species of the 4 - $\mathrm{LD}$ polymers changed from only SC-crystallites to an amorphous form and then to only homo-crystallites (during non-isothermal crystallization) or from only SC-crystallites to only homo-crystallites (during precipitation). The branching architecture rather than the stereo diblock architecture disturbed the simultaneous formation of SC-crystallites and homocrystallites. The crystallite growth morphology during heating depended on the crystalline species, and the crystallite growth morphology during slow cooling was not altered by the crystalline species or block copolymerization. Factor A decreased $T_{\mathrm{g}}$, and the higher $T_{\mathrm{cc}}$ values of the 4-L/4-D blends and 4-LD polymers compared with those of the 1-L/1-D blends were due to disturbed segmental diffusion (Factor B). In addition, the high $T_{\mathrm{cc}}$ values of the 1-LD polymers compared with those of the 1-L/1-D blends were due to disturbed segmental diffusion (Factor D).

\section{CONFLICT OF INTEREST}

The authors declare no conflict of interest.

\section{ACKNOWLEDGEMENTS}

This research was supported by JSPS KAKENHI grant number 16K05912 and MEXT KAKENHI grant number 24108005.

1 Slager, J. \& Domb, A. J. Biopolymer stereocomplexes. Adv. Drug Deliv. Rev. 55, 549-583 (2003).

2 Tsuji, H. Poly(lactide) stereocomplexes: formation, structure, properties, degradation, and applications. Macromol. Biosci. 5, 569-597 (2005).

3 Tsuji, H. Poly(lactic acid) stereocomplexes: a progress of decade. Adv. Drug Del. Rev. doi:10.1016/j.addr.2016.04.017 (in press),

4 Tsuji, H., Ikada, Y., Hyon, S. H., Kimura, Y. \& Kitao, T. Stereocomplex formation between enantiomeric poly(lactic acid). VIII. Complex fibers spun from mixed solution of poly(D-lactic acid) and poly(L-lactic acid). J. Appl. Polym. Sci. 51, 337-344 (1994).

5 Serizawa, T., Yamashita, H, Fujiwara, T., Kimura, Y. \& Akashi, M. Stepwise assembly of enantiomeric poly(lactide)s on surfaces. Macromolecules 34, 1996-2001 (2001)

6 Takasaki, M., Ito, H. \& Kikutani, T. Development of stereocomplex crystal of polylactide in high-speed melt spinning and subsequent drawing and annealing processes. J. Macromol. Sci. Phys. 42B(3-4 SPEC.), 403-420 (2003).

7 Fujita, M., Sawayanagi, T., Abe, H., Tanaka, T., Iwata, T., Ito, K., Fujisawa, T. \& Maeda, M. Stereocomplex formation through reorganization of poly(L-lactic acid) and poly(D-lactic acid) crystals. Macromolecules 41, 2852-2858 (2008).

8 Ishii, D., Ying, T. H., Mahara, A., Murakami, S., Yamaoka, T., Lee, W. \& Iwata, T. In vivo tissue response and degradation behavior of PLLA and stereocomplexed PLA nanofibers. Biomacromolecules 10, 237-242 (2009).

9 Li, L., Zhong, Z., De Jeu, W. H., Dijkstra, P. J. \& Feijen, J. Crystal structure and morphology of poly(L-lactide-b-D-lactide) diblock copolymers. Macromolecules 37, 8641-8646 (2004)

10 Sugai, N., Yamamoto, T. \& Tezuka, Y. Synthesis of orientationally isomeric cyclic stereoblock polylactides with head-to-head and head-to-tail linkages of the enantiomeric segments. ACS Macro Lett. 1, 902-906 (2012).

11 Tsuji, H., Wada, T., Sakamoto, Y. \& Sugiura, Y. Stereocomplex crystallization and spherulite growth behavior of poly(L-lactide)- $b$-poly(D-lactide) stereodiblock copolymers. Polymer 51, 4937-4947 (2010).

12 Masutani, K., Lee, C. W. \& Kimura, Y. Synthesis and properties of stereo di- and tri-block polylactides of different block compositions by terminal diels-alder coupling of poly-L-lactide and poly-D-lactide prepolymers. Polym. J. 45, 427-435 (2013).

13 Sakamoto, Y. \& Tsuji, H. Stereocomplex crystallization behavior and physical properties of linear 1-arm, 2-arm, and branched 4-arm poly(L-lactide)/poly(D-lactide) blends: effects of chain directional change and branching. Macromol. Chem. Phys. 214, 776-786 (2013).

14 Shao, J., Sun, J., Bian, X., Cui, Y., Li, G. \& Xuesi, C. Investigation of poly(lactide) stereocomplexes: 3-armed poly(L-lactide) blended with linear and 3-armed enantiomers. J. Phys. Chem. B 116, 9983-9991 (2012).

15 Isono, T., Kondo, Y., Otsuka, I., Nishiyama, Y., Borsali, R., Kakuchi, T. \& Satoh, T. Synthesis and stereocomplex formation of star-shaped stereoblock polylactides consisting of poly(L-lactide) and poly(D-lactide) arms. Macromolecules 46, 8509-8518 (2013).

16 Tsuji, H. \& Matsumura, N. Stereocomplex crystallization of star-shaped four-armed stereo diblock poly(lactide)s with different molecular weights: isothermal crystallization from the melt. Macromol. Chem. Phys. 217, 1547-1557 (2006).

17 Han, L., Shan, G., Bao, Y. \& Pan, P. Exclusive stereocomplex crystallization of linear and multiarm star-shaped high-molecular-weight stereo diblock poly(lactic acid)s. J. Phys. Chem. B 119, 14270-14279 (2015).

18 Tsuji, H., Matsumura, N. \& Arakawa, Y. Stereocomplex crystallization and homocrystallization of star-shaped four-armed stereo diblock poly(lactide)s with different L-lactyl unit contents: isothermal crystallization from the melt. J. Phys. Chem. B 120, 1183-1193 (2016).

19 Gedde U. W. in Polymer Physics Ch. 8, 170-98 (Chapman \& Hall, London, UK, 1995).

20 Tsuji, H., Tamai, K., Kimura, T., Kubota, A., Tahahashi, A., Kuzuya, A. \& Ohya, Y. Stereocomplex- and homo-crystallization of blends from 2-armed poly(L-lactide) and poly(D-lactide) with identical and opposite chain directional architectures and of 2-armed stereo diblock poly(lactide). Polymer 96, 167-181 (2016).

Supplementary Information accompanies the paper on Polymer Journal website (http://www.nature.com/pj) 